\title{
FOUCAULT: SUA ESCRITA, SUA VIDA, E A PSICANÁLISE
}

\author{
FOUCAULT: HIS WRITING, HIS LIFE, AND THE PSYCHOANALYSIS
}

FOUCAULT: SUS ESCRITOS, S VIDA, Y EL PSICOANÁLISIS

Sérgio Laia*

\begin{abstract}
RESUMO
Este texto procura investigar como a ambiguidade de Foucault com relação à psicanálise não se restringe a suas formulações de como a descoberta freudiana subverte as malhas do poder e também é envolvida pelas tramas do poder. Este texto, então, enfocará essa ambiguidade no modo como Foucault (sem qualquer recurso à experiência psicanalítica) se serve do que escreve para avançar em questóes que, voltadas para a filosofia, a política, o saber, não deixam de se articular também ao que toca seu corpo e sua vida. Nesse contexto, as formulaçôes de Lacan sobre o parlêtre ("falasser") e o "sinthoma" serão importantes para elucidar como Foucault aplicou à sua vida e à sua obra o que ele próprio chamou de "estética da existência".
\end{abstract}

Palavras-chave: Vida. Obra. Escrita. Sinthoma. Estética da existência.

\begin{abstract}
This text investigates how Foucault's ambiguity with regard to psychoanalysis is not restricted to his formulations of how the Freudian discovery both subverts the nets of power and is involved by its plots. There is an ambiguity in the way Foucault uses his writing to advance in questions regarding not only philosophy, politics and knowledge, but also his body and his life, and this without any analytical experience. Lacan's formulation concerning the parlêtreand the sinthomewill be important to elucidate how Foucault applied to his life and his writings what he called "the aesthetics of existence".
\end{abstract}

Keywords: Life. Writings. Work. Sinthome. Aesthetics of existence.

\footnotetext{
Conferência apresentada na mesa Acordes finos: Foucault e a psicanálise, no dia 19 de outubro de 2017, durante o evento 91 anos com Michel Foucault: o belo perigo, realizado pela Fundação Hospitalar do Estado de Minas Gerais (Fhemig) e pela Pontifícia Universidade Católica de Minas Gerais (PUC Minas).

*Doutor em Letras e mestre em Filosofia pela Universidade Federal de Minas Gerais (UFMG), professor do Curso de Psicologia e do Mestrado em Estudos Culturais Contemporâneos da Universidade Fumec (Fundação Mineira de Educação e Cultura), pesquisador com projeto pela FAPEMIG (Fundação de Amparo à Pesquisa do Estado de Minas Gerais) e pelo Programa de Pesquisa e Iniciação Científica (Propic) da Universidade Fumec, psicanalista, analista da escola (AE - 2017-2020) e analista membro da escola (AME) pela Escola Brasileira de Psicanálise (EBP) e pela Associação Mundial de Psicanálise (AMP). E-mail: laia.bhe@terra.com.br.
} 


\section{RESUMEN}

Este texto busca investigar cómo la ambigüedad de Foucault con relación al psicoanálisis no debe ser restricta a sus formulaciones sobre los modos como la descubierta freudiana ha subvertido las redes de poder y se encuentra también involucrada en sus tramas. Entonces, el este texto busca focalizar esta ambigüedad en el modo como (sin ninguno recurso a la experiencia analítica) Foucault utiliza sus escritos para hacer avanzar cuestiones que, orientadas hacia la filosofía, la política y los saberes, son también articuladas a su cuerpo y a su vida. En este contexto, las formulaciones de Lacan a propósito del parlêtre y del sinthoma serón muy importantes para elucidar cómo Foucault aplicó, a su vida y a su obra, el que él mismo llamó de "estética de la existencia".

Palabras clave: Vida. Obra. Escritura. Sinthoma. Estética de la existencia.

"Cada um de meus livros representa uma parte de minha história. Por uma ou outra razão, me foi dada a ocasião de provar ou de viver essas coisas." (Foucault, 1982, p. 777)

Meu trabalho e minha vida como psicanalista não me têm permitido acompanhar, como eu gostaria (e, ao ser convidado para esta mesa, talvez mesmo deveria), a atualidade da "fortuna crítica" dedicada aos textos de Foucault, inclusive quanto à sua relação com a psicanálise. Entretanto, apesar dessa "falha" acadêmico-universitária, meu apreço por esse filósofo, sua importância em minha formação intelectual e também psicanalítica não me fizeram hesitar um segundo sequer quando Juliana Motta me convidou para participar deste evento que celebra, bem diversamente do que é o costume, uma contagem não redonda, ou seja, uma data ímpar e, em vez de uma ausência ou uma distância relacionada ao nascimento de quem não está mais entre nós, o modo como estamos com Foucault, há 91 anos.

\section{UMA AMBIGUIDADE}

D evido a essa minha falha acadêmico-universitária quanto à atualização da fortuna crítica sobre Foucault e a psicanálise, retorno a um livro publicado em 1988 e derivado do que foi, então, a dissertação de mestrado de Ernane Chaves, meu colega de mesa neste evento (Chaves, 1988). Mas esse retorno se justifica também porque, pelas leituras de Foucault que continuo fazendo sempre que posso, ainda considero esse livro importante para quem se interessa pelo modo como Foucault se refere à psicanálise em seus textos. É certo que Chaves (1988) continuou produzindo muitas outras referências valiosas sobre a obra foucaultiana, mas esse livro, mesmo concentrando sua trajetória apenas em História da loucura e no primeiro volume de História da sexualidade (Foucault, 
1972; 1976), apresenta-nos uma palavra que, presente já na introdução e retornando na conclusão, parece-me dar o tom das relações de Foucault com a psicanálise: "ambiguidade" (Chaves, 1988, pp. 6; 126).

Essa ambiguidade se ressalta ao longo dos textos em que Foucault se refere à psicanálise porque o veremos tanto reconhecer, frente à psiquiatria, à psicologia e às ciências humanas, as diferenças que permitiriam à psicanálise não se associar às malhas do poder, quanto as dificuldades da descoberta freudiana para romper com as estruturas de dominação. Tal relação de Foucault com a psicanálise se valeria, inclusive, do "vigor", da "fecundidade" e da "situação liminar e ambígua" do referencial freudiano "no interior das estruturas de poder-saber dominantes" (Chaves, 1988, p. 131). Assim, "a grande questão" é de "procurar compreender por que, apesar de tantos deslocamentos reconhecidos pelo próprio Foucault", suas proposiçôes sobre a psicanálise o levam sempre a afirmar que "tais deslocamentos não são suficientes, não bastam para romper com as sólidas estruturas de dominação" e, assim, haveria sempre, para Foucault, uma "insuficiência da Psicanálise para se tornar um foco de resistência nas malhas do poder" (Chaves, 1988, p. 143-144).

Sem dúvida, é bastante enriquecedor, para os estudos foucaultianos e para os estudos psicanalíticos, elucidar em que pontos Foucault destaca os modos como a psicanálise é apreendida nessas malhas do poder e como lhe acontece também escapar e até ser uma via de fuga nessa trama. Também é instigante verificar em que Foucault teria ou não razão nessa ambiguidade com que localiza a psicanálise nessas relações com o poder e com o que também chamou de processos de produção de subjetividades. Porém, aqui, inclusive por minha formação como analista lacaniano, vou preferir seguir outra via na qual não é o que Foucault demarca como ambiguidade entre a psicanálise e o poder que vai me interessar: privilegiarei alguns posicionamentos nos quais Foucault chegou a conclusóes que me parecem perfeitamente psicanalíticas, embora ele jamais pretendeu ser um psicanalista, realizou uma análise pessoal ou tomou a psicanálise como uma ferramenta para suas pesquisas.

\section{FOUCAULT COMO FALASSER (PARL $\hat{E} T R E)$}

No verão-outono de 1968, como nos informam Artières (2016) e Carvalho (2016), Foucault (2016) realizou com o crítico literário francês Claude Bonnefoy algumas conversas, visando à edição de um livro, mas esse projeto editorial não vingou, exceto de modo incompleto e póstumo (mas não menos precioso e genial), com a publicação, em francês, em 2012, de $O$ belo perigo que, agora, serviu também de título para este evento em que nos reunimos para celebrar 
91 anos com Foucault. Foi Fernando Casula, em uma conversa em torno do convite para a realização desta minha conferência, que me chamou atenção para esse livro, evocando, inclusive, a possibilidade de que eu viesse a levá-lo em conta nas minhas elaborações sobre Foucault e a psicanálise. Sem dúvida, a partir desse livro, encontrei algumas pistas para apresentar aqui, de modo talvez ainda incipiente e a ser melhor tematizado em futuras ocasióes, outro tipo de ambiguidade que envolve as relações de Foucault com a psicanálise.

Logo de início, Foucault destaca que o convite feito por Bonnefoy e aceito prontamente não era para repetir o que já havia dito em outras situações e tampouco eram de "confidências" referentes à sua "vida" ou a seus sentimentos: não se tratava "nem [...] da obra nem da explicação, nem tampouco da confidência" (Foucault, 2016, p. 35). Ao mesmo tempo, um pouco mais adiante, Foucault (2016, p. 37) demarca como, ao falar "de um autor" em seus textos, ele sempre procurava, quanto a esse "autor", "não levar em conta seus fatores biográficos", seu "contexto social e cultural" e o "campo de conhecimento" de onde advinha sua formação, de modo que tentava, assim, "abstrair daquilo que normalmente se chamaria sua psicologia para fazê-lo funcionar como um puro sujeito falante". Porém, naquelas conversas, em 1968, concernentes à sua própria relação com a escrita, Foucault (2016, p. 37) sustenta que fará "uma retratação" literalmente apresentada nos seguintes termos: "Voltar contra mim mesmo o sentido do discurso que desenvolvi a propósito dos outros". Conversando com Bonnefoy no fim dos anos 1960, portanto, Foucault (2016), nessa "retratação", acaba fazendo confidências, apresentando alguns dados pessoais que elucidam o lugar e a função da escrita em sua vida, mas sem, a meu ver, deixar de apresentar também como o que chama de "puro sujeito falante". Logo, o que ele faz não é uma psicobiografia, não é uma explicação de sua produção escritural baseada em elementos de sua vida pessoal. Foucault (2016) antecipa, em 1968, o que, já no fim de sua vida, em 1983, vai ser apresentado em outra entrevista nos seguintes termos:

No fundo, alguém que é escritor não faz simplesmente sua obra em seus livros, no que ele publica $[\ldots]$ sua obra principal, no final das contas, é ele mesmo escrevendo seus livros. Essa relação dele com seus livros, de sua vida com seus livros, é o ponto central, a morada (foyer) de sua atividade e de sua obra. A vida privada de um indivíduo, suas escolhas sexuais e sua obra estão ligadas entre elas, não porque a obra traduz a vida sexual, mas porque ela compreende a vida tanto quanto o texto. A obra é mais que a obra: o sujeito que escreve faz parte da obra (Foucault, 1994a, p. 607).

Essa conjugação (que atravessa toda a atividade escritural e boa parte da vida concernentes a Foucault) entre "puro sujeito falante", "vida", "obra" e "escolhas sexuais" parece-me possível de ser aproximada do que Lacan (1975), em um 
seminário pronunciado em 1972-1973, designou como parlêtre ("falasser"). Miller (1998) elucida essa noção lacaniana como o sujeito destituído de toda substância de seu ser pelo uso mesmo da fala e afetado pelo corpo. A noção de parlêtre ("falasser") me parece particularmente oportuna para ser aplicada a essas considerações de Foucault (1994a; 2016) sobre o modo como a escrita atravessalhe a vida, porque, nela, Lacan (1975) conjuga "fala" (parle), "ser" (être) e "letra" (letre), ou seja, escrita.

Adotando uma perspectiva confessional (Foucault, 1976) que, como sabemos, serve-lhe também para criticar certa retenção da psicanálise nas malhas do poder, o próprio Foucault (2016) aborda, em 1968, de início, sua relação à escrita em um nível, digamos, bem elementar e, portanto, como ele mesmo evoca, nada sagrado, porque concerne pura e simplesmente à grafia. Ficamos sabendo, então, do quanto sofreu por não conseguir fazer uma letra efetivamente legível e de como parte de sua vida escolar foi atravessada por preenchimento de cadernos de caligrafia. Porém, nessa perspectiva confessional, interessa-me mais destacar o modo como escrever, no sentido de ter uma produção escritural, ganhou-lhe um lugar determinante na vida, no sentido de Foucault (2016, p. 37) passar a "sentir vontade de escrever", aos 30 anos. Esse destaque também procura valerse do quanto essa vontade pautou sua vida e sua satisfação desde então porque, mais para o final da conversa com Bonnefoy, Foucault (2016, p. 64) afirmará o quanto que "é a felicidade de existir que depende da escrita".

Para dimensionarmos ainda mais em que contexto a escrita ganhou essa dimensão para Foucault (2016, pp. 38-39), considero importante citar ainda suas seguintes palavras, pronunciadas em 1968:

Para chegar a descobrir o prazer possível da escrita, foi preciso que eu estivesse no exterior. Estava então na Suécia, obrigado a falar ou sueco, que conheço muito mal, ou inglês, que pratico com bastantes dificuldade [...] Via as palavras que queria dizer se travestirem, simplificarem-se, tornarem-se como que marionetes irrisórias à minha frente no momento em que as pronunciava [...]. Naquela Suécia onde eu devia falar uma língua que me era estrangeira, compreendi que podia habitar minha língua [...] como sendo o lugar mais secreto, porém mais seguro de minha residência nesse lugar sem lugar que é o país estrangeiro [...] Acho que foi isso que me deu vontade de escrever. Entre prazer de escrever e possibilidade de falar, existe certa relação de incompatibilidade. Ali onde não é mais possível falar, descobre-se o encanto secreto, difícil, um pouco perigoso de escrever

Assim, a escrita vem para fazer face ao exílio, ao estrangeiro que Foucault passa a habitar com seu corpo sob o nome de Suécia e, mais ainda, para lhe ser um refúgio frente à impossibilidade de falar. A biografia desse filósofo publicada, em 1989, por Eribon (1990, p. 43) sustenta também que, "entre os motivos de sua partida para a Suécia, em 1955", estavam os "impasses em que se sentia 
encerrado" com relação à própria homossexualidade. Havia também, nesse mesmo contexto, pouco após sua partida para a Suécia, o súbito rompimento com Jean Barraqué, o músico contemporâneo por quem Foucault estava apaixonado (Eribon, 1990, p. 80).

Esse silêncio (impossibilidade de falar o que afeta o corpo como estrangeiro e que a escrita procura eludir) remete-nos também ao pai de Foucault (2016, pp. 40-41) porque, referindo-se à profissão paterna de médico-cirurgião, localiza-o como quem "não [...] fala", como "aquele que escuta" e que só vai pronunciar "as palavras breves do diagnóstico e da terapêutica". Esse tipo de reconstrução do pai dá lugar, em 1968, a uma invenção do pai através da escrita:

Imagino que haja em minha caneta uma velha herança do bisturi [...] Substituí o inapagável da cicatriz pelo signo perfeitamente apagável e razoável da escrita [...] A folha de papel talvez seja, para mim, o corpo dos outros [...] É essencialmente lidar com os outros na medida em que já estão mortos. Falo de certa forma sobre o cadáver dos outros (Foucault, 2016, pp. 44-45).

Daí, em 1968, Foucault (2016), fiel ao que vai trabalhar, em 1969-1970, em sua célebre conferência sobre O que éum autor, Foucault (1994b), não se apresenta propriamente como sendo um "autor" ou tendo uma "obra". Ele prefere colocarse como uma espécie de legista quanto ao que escreve, "um diagnosticador" cujo "trabalho consiste em trazer à luz através da própria incisão da escrita algo que seja a verdade daquilo que está morto" (Foucault, 2016, p. 48). Verificamos que a referência ao pai-médico, assim como aos avôs também médicos, não implica colocar-se na sequência da linhagem ou da tradição filial, porque inclui ainda um distanciamento, uma diferença que me autoriza a afirmar, como psicanalista de orientação lacaniana, que Foucault faz, com sua escrita, um uso do pai no qual, como nos ensina Lacan (2007) em seu Seminário de 1975-1976, um parlêtre (falasser), através do sinthoma, dispensa-se o pai por se servir dele. Nos termos mesmos de Foucault (2016):

Como meu pai e meus avôs, quero fazer um diagnóstico. Só que, diferente deles - e é nisso que me separo e me volto contra eles - esse diagnóstico, quero fazê-lo a partir da escrita, quero fazê-lo nesse elemento do discurso que os médicos, normalmente, reduzem ao silêncio (p. 49).

A meu ver, a própria via aberta pelo legista-Foucault de extrair, com a escrita, a verdade do que está morto, ou seja, essa relação escrita-morte, é um modo de ele demarcar sua diferença com relação à tradição médico-familiar. Afinal, como pude aprender nas aulas de José de Anchieta Corrêa (que também faz parte deste evento intitulado $O$ belo perigo), a morte, embora faça parte cotidianamente da prática médica, é também, paradoxalmente, o que os médicos, em geral, não querem saber. 
Além disso, o sujeito-Foucault, como nos mostra Eribon (1990, p. 41), foi particularmente assolado pela morte no início de sua juventude: tentou suicídio em 1948, aos 22 anos, e, segundo o relato de um de seus amigos "era obcecado por essa ideia", a ponto de, diante de uma pergunta coloquial sobre aonde estava indo, outro colega se surpreende com a seguinte resposta: "Vou comprar uma corda para me enforcar". O médico da École Normale, onde Foucault estudava nesse período de sua vida, limitou-se, por sigilo profissional, a atribuir tais perturbações de Foucault aos impasses que a homossexualidade lhe colocava no fim dos anos 1940 e início dos anos 1950. Assim, quase uma década depois, quando, aos 30 anos, Foucault descobre e começa a apurar seu gosto pela escrita e está prestes a se tornar efetivamente Foucault, uma transmutação se processa: a morte que lhe tomava o corpo é transposta para os corpos mortos que ele passa a perscrutar com sua caneta-bisturi; o silêncio que a tradição médico-paternoavuncular ganha espessura e mesmo voz com o que Foucault passa a escrever; aquilo que "não tinha" sido "visto inicialmente", inclusive pelo próprio Foucault (2016, p. 49), é trazido à luz, pela escrita, que retoma ("através da brancura e da inércia da morte") não "a vibração perdida da vida", mas o que é designado como "desdobramento meticuloso da verdade".

Utilizando, então, de novo termo sinthoma que, ao logo do Seminário de 19751976, Lacan (2007) pôde tematizar a partir de sua experiência como analista e de sua leitura de James Joyce, eu lhes diria que, aos 30 anos, pela dimensão que a escrita passa a ter para Foucault, este encontra, no frio e na terra incógnita que lhe foi "Suécia", a via de seu "sinthoma".

\section{SINTHOMA E ESTÉTICA DA EXISTÊNCIA}

O encontro dessa via, que certamente poderá ser mais bem elucidado, em outras produções de textos, com novas referências extraídas da vida e da obra de Foucault, parece-me confirmar-se também a partir de dois outros elementos.

O primeiro elemento diz respeito ao próprio modo como, já em 1968, Foucault (2016, p. 59) explicita para Bonnefoy por que, por exemplo, um Roussel e um Artaud (com a loucura que lhes tomaram a vida e com o que escreveram) lançam à razão que silencia a loucura enigmas diante dos quais é ela, a razão, que passa a silenciar-se. Nessa explicitação, cotejo o modo como Foucault (2016) se refere a Roussel, a Artaud, à razão, por um lado, e a designação, por outro lado, feita por Lacan $(2001$; 2007), respectivamente em um escrito de 1972 e no já citado Seminário de 1975-1976, de que o "dito esquizofrênico" encontrase "fora de discurso" e de que, no caso do escritor James Joyce, sem qualquer recurso à experiência psicanalítica, a escrita serviu-lhe de sinthoma para fazer 
frente à carência simbólica do pai em sua vida e em seu corpo. Afinal, cavando, com suas obras enigmáticas e perturbadoras, um lugar no "discurso" da razão, Roussel e Artaud, segundo Foucault (2016), realizam um ato realmente inaudito. Laurent (2005), valendo-se de duas expressões wittgensteinianas e da experiência psicanalítica do fim de análise formalizada por Lacan, permite-me destacar esse ato como o que faz a "linguagem privada" do gozo de cada um ganhar expressão, através de obras tramadas como "sinthomas", em uma "linguagem pública". Assim, sobre um Roussel e um Artaud, escutaremos Foucault (2016) dizer o seguinte:

O que me admira aqui, aquilo sobre o que me interrogo é[...] como é que uma obra dessas, que vem de um indivíduo que a sociedade desclassificou - e consequentemente excluiu - como doente, pode funcionar, e funcionar de uma maneira absolutamente positiva, no interior de uma cultura? [...] Imediatamente, ou quase, elas [essas obras de um Roussel e de um Artaud] passaram a fazer parte do nosso universo de discurso[...] É esse funcionamento positivo do negativo que nunca cessou de me inquietar. Não me coloco o problema da relação obra-doença, mas da relação exclusão-inclusão: exclusão do indivíduo, de seus gestos, de seu comportamento, de seu caráter, daquilo que ele é, inclusão muito rápida e, no fim das contas, bastante fácil, de sua linguagem (pp. 59-60).

O segundo elemento pelo qual a escrita serve para Foucault perfazer a via de seu próprio sinthoma concerne ao modo como, já no fim de sua vida, a morte passou a incidir no seu corpo acometido então pela Aids e de como isso transforma sua investigação e seu estilo escritural. Aqui, também, o uso "sinthomático" da escrita se faz presente, a meu ver. Como certa vez me fez notar Thereza Calvet, em uma conversa mantida à época em que ela foi minha orientadora no Mestrado de Filosofia da Universidade Federal de Minas Gerais, é no mundo hipersexualizado dos anos 1980 que Foucault (1984a; 1984b) vai retornar à antiguidade grecoromana para tematizar como o "uso dos prazeres" e o "cuidado de si" podem dar lugar a uma "estética da existência" para que se possa fazer da vida "uma obra de arte". Além disso, é também esse uso "sinthomático" da escrita por Foucault que posso ler, hoje, na seguinte passagem de uma conferência que Miller (1988, pp. 81-82) em um dos primeiros eventos realizados em homenagem a Foucault:

Maurice Blanchot nota a diferença de estilo dos últimos livros [de Foucault]: apaziguado, diz ele, sem a paixão que tornava fulgurantes seus outros textos. Mas, de onde vem esse apaziguamento na obra mesma que[...] enunciava a ambição de nos desembaraçar (affranchir)? [...] Se esse movimento se detém na Grécia antiga, não será por essa razão que Foucault descobre... aquém e não mais além da época contemporânea esse ponto de apoio que lhe faltava? Essa utopia realizada não de uma sexualidade feliz, mas de um corpo voltado para o prazer plural, onde as coisas do amor, com efeito, não formariam um conjunto unificado pela função do falo castrado, esse mais além do corte moderno, que Foucault não parava de convocar por seus anseios, por sua arqueologia, esse mais além a partir da qual ele 
se revirava para nossa época para descrever o fim dela, esse mais além que ele tinha achado agora no mais aquém figurado aqui pela Grécia, é por aí, de minha parte, que eu me explico o apaziguamento final de sua busca.

Aludida por um psicanalista com relação aos últimos grandes exercícios de escrita e de invenção sustentados por Foucault (1984a e; 1984b), essa perspectiva de as "coisas do amor" não formarem "um conjunto unificado pela função do falo castrado" pode soar estranha ao que é veiculado pela doxa psicanalítica com relação à importância da castração e do próprio falo. Entretanto, mais além dessa doxa, parece-me importante assinalar que o mesmo Miller (2011), em um curso dado em 2008 e 2009, muitos anos depois dessa homenagem a Foucault e em um contexto específico à experiência psicanalítica, vai apresentar a perspectiva de que o falo, especialmente no âmbito do que Lacan (2007), no Seminário de 1975-1976, passou a escrever como "sinthoma", extrapola "o regime da castração, [...] o regime das faltas, dos substitutos de faltas": o falo passa a se referir ao gozo impossível de negativizar, viabilizando uma "nova aliança" do falasser (parlêtre) com essa satisfação que, sem se deixar negativizar, insiste em pulsar em seu corpo. Não é esse tipo de "nova aliança" que Foucault, com sua vida e sua escrita, buscou e que, sobretudo em seus últimos dois livros, ele procura transmitir? Certamente, explorar e responder essa pergunta iria me levar a caminhos mais além desta conferência, mas apresentá-la assim, mesmo sem maiores desdobramentos, neste final, não deixa de ser mais um modo pelo qual procuro demarcar aqui essa outra ambiguidade que permeia as referências de Foucault à psicanálise quando elas não se limitam às suas investigações históricofilosóficas, mas se abrem para os modos como ele se serve do que escrevia para avançar nos enigmas que lhe permeavam a vida. 


\section{REFERÊNCIAS}

Artières, P. (2016). Fazer a experiência da fala. In. M. Foucault, $O$ belo perigo. (pp. 13-28). Belo Horizonte: Autêntica.

Carvalho, J. M. (2016). Foucault e a arte da escrita. In M. Foucault, $O$ belo perigo. (pp. 7-11). Belo Horizonte: Autêntica.

Chaves, E. (1988). Foucault e a psicanálise. Rio de Janeiro: Forense Universitária.

Eribon, D. (1990). Foucault: uma biografia. São Paulo: Companhia das Letras.

Foucault, M. (1972). Histoire de la folie à l'âge classique. Paris: Gallimard.

Foucault, M. (1976). Histoire de la sexualité: la volonté de savoir. (Vol. 1). Paris: Gallimard.

Foucault, M. (1982). Vérité, pouvoir et soi. In M. Foucault, Dits et écrits. (Vol. 4, pp. 777-783). Paris: Gallimard.

Foucault, M. (1984a). Histoire de la sexualité: l’usage des plaisirs. (Vol. 2). Paris: Gallimard.

Foucault, M. (1984b). Histoire de la sexualité: le souci de soi. (Vol. 3). Paris: Gallimard.

Foucault, M. (1994a). Archéologie d'une passion. In M. Foucault, Dits et écrits. (Vol. 4, pp. 599-608). Paris: Gallimard.

Foucault, M. (1994b). Qu'est-ce qu'un auteur? In M. Foucault, Dits et écrits. (Vol. 1, pp. 789-821). Paris: Gallimard.

Foucault, M. (2016). O belo perigo. Belo Horizonte: Autêntica.

Lacan, J. (1975). Le séminaire. Livre 20: encore. Paris: Seuil.

Lacan, J. (2001). Leétourdit. In Lacan, J. Autres écrits. (pp. 449-496). Paris: Seuil.

Lacan, J. (2007). O seminário. Livro 23: o sinthoma. Rio de Janeiro: Zahar.

Laurent, É (2005). Da linguagem pública à linguagem privada, topologia da passagem. Opção lacaniana, (42), 57-59.

Miller, J.-A. (1988). Michel Foucault et la psychanalyse. In M. Foucault, Philosophe: recontre internationale. (pp. 77-83). Paris: Seuil. 
Miller, J.-A. (1998). O osso de uma análise. Salvador: Agente.

Miller, J.-A. (2011). Perspectivas dos escritos e outros escritos de Lacan. In Entre desejo e gozo. (pp. 7-226). Rio de Janeiro: Zahar. 